\title{
Shell nacre ultrastructure and depressurisation dissolution in the deep-sea hydrothermal vent mussel Bathymodiolus azoricus
}

Eniko Kadar • Antonio G. Checa •

Alfredo Damasceno-Oliveira $\cdot$ Jorge P. Machado

Published online: 6 September 2007

(C) Springer-Verlag 2007

\section{Erratum to: J Comp Physiol B}

DOI 10.1007/s00360-007-0178-z

The original version of this article unfortunately contained a mistake. The spelling of the Alfredo Damasceno-Oliveira name was incorrect.

The online version of the original article can be found under doi:10.1007/s00360-007-0178-z.

E. Kadar $(\bowtie)$

Department of Oceanography and Fisheries, IMAR Centre of the University of the Azores, Cais de Santa Cruz, 9901-862 Horta, Portugal e-mail: enikokadar@notes.horta.uac.pt

\section{A. G. Checa}

Department of Stratigraphy and Paleontology,

University of Granada, Avenida Fuentenueva s/n, 18071 Granada, Spain

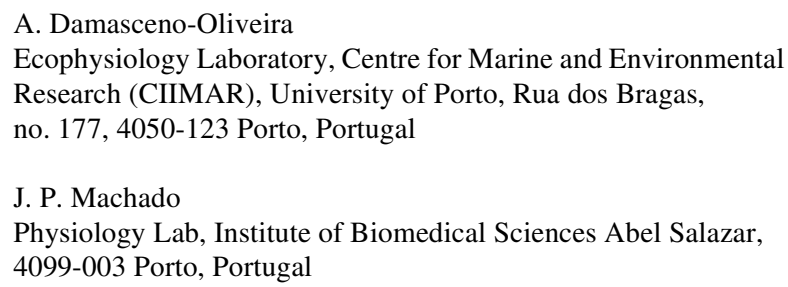

